\title{
Hazardous effect of the maintenance dose of iron sucrose versus iron dextran on oxidative burst activity of neutrophils in patients on regular hemodialysis; a pilot study
}

\author{
Iman Ibrahim Sarhan $^{1}{ }^{\circledR}$, Maha Abdelmoneim Behairy ${ }^{*^{\circledR}}$, Hoda Mohamed El Sayed ${ }^{(\mathbb{}}$, Doaa Mohamed \\ Abdelaziz $^{3}$ \\ ${ }^{1}$ Internal Medicine and Nephrology Department, Ain Shams University, Cairo, Egypt \\ ${ }^{2}$ Internal Medicine and Immunology Department, Ain Shams University, Cairo, Egypt \\ ${ }^{3}$ Clinical Pathology Department, Faculty of Medicine, Ain Shams University, Cairo, Egypt
}

\section{A R T I C L E I N F O}

\section{Article Type:}

Original

\section{Article History:}

Received: 30 January 2019

Accepted: 10 May 2019

Published online: 3 June 2019

\section{Keywords:}

Iron therapy

Neutrophils

Hemodialysis

Flow-cytometry

End-stage renal disease

Oxidative burst test

Reactive oxygen species

Chronic kidney disease

\begin{abstract}
A B S T R A C T
Introduction: Intravenous (IV) iron which is a potent pro-oxidant may decrease the phagocytic function of neutrophils and subsequently leads to repeated bacterial infections in patients on chronic regular hemodialysis (HD).

Objectives: We aimed to evaluate the effect of IV iron dextran versus iron sucrose on oxidative burst activity of neutrophils in HD patients.

Patients and Methods: A crossover study was included 20 prevalent HD patients were randomly divided into two groups; 10 patients each. Each group received a single dose of $100 \mathrm{mg}$ iron sucrose or iron dextran then shifted to the other type after 4 weeks as a washout period. Patients with evidence of acute infections, diabetes mellitus, chronic liver disease, active collagen disease or any other acquired immune deficiency diseases were excluded. Patients on immunosuppressive drugs or with hypersensitivity to iron therapy or evidence of iron overload (TSAT $>50 \%$ and/or ferritin $>800 \mathrm{ng} / \mathrm{mL}$ ) were also excluded. Erythropoietin maintenance dose was given to all patients. Urea reduction ratio (URR \%), C-reactive protein (CRP) titer, complete blood picture and iron study were conducted. Neutrophil oxidative burst test was performed by flow-cytometry with an estimation of stimulation index before and after IV iron dosage.

Results: Twenty patients ( 9 males, 11 females; mean age $49.40 \pm 9.02$ years) on chronic HD for a mean time of $10 \pm 7.32$ years. After $100 \mathrm{mg}$ of IV iron infusion in HD patients, a highly significant difference in oxidative burst test of neutrophil cells before and after administration of iron regardless of its type was detected $(P<0.01)$. This change over time is not significantly different between two types of iron $(P>0.05)$. However, a significant increase in CRP titer after administration of iron dextran was seen $(P=0.016)$.

Conclusion: Maintenance dosage of either IV iron sucrose or iron dextran (100 mg) had a hazardous effect on the neutrophilic phagocytosis demonstrated by the significant rise in the oxidative burst index in HD patients.
\end{abstract}

\section{Implication for health policy/practice/research/medical education:}

In a clinical study on a group of regular hemodialysis patients we found, both commercial types of IV iron (dextran or sucrose) significantly increased the neutrophil cells oxidative burst stimulation index after 48 hours. Chronic renal failure is becomingly increasing in incidence and there is a world-wide administration of iron preparations in these patients. Better understanding and cautious use of these preparations are needed to get the most benefit from it while reducing the risks.

Please cite this paper as: Sarhan II, Behairy MA, El Sayed HM, Abdelaziz DM. Hazardous effect of the maintenance dose of iron sucrose versus iron dextran on oxidative burst activity of neutrophils in patients on regular hemodialysis; a pilot study. J Nephropharmacol. 2020;9(1):e03. DOI: 10.15171/npj.2020.03. 


\section{Introduction}

Intravenous (IV) iron preparations are widely used in the treatment of anemia in end-stage renal disease (ESRD) patients on regular hemodialysis (HD). Some concerns are related to using IV iron in ESRD patients. These include infections, hypersensitivity reactions, oxidative injury, iron overload, inflammation and immune dysregulation.

There are numerous studies regarding the association between iron and infection. One study found a significantly higher rate of bacteremia with iron sucrose compared to ferric gluconate (1). Another study reported a significant association between iron sucrose and catheter-related sepsis but not with iron dextran (2). Other studies opposed the association between iron and infection $(3,4)$. Recent studies focusing on serum ferritin and its association with infection (5-8).

Neutrophils are the most abundant type of granulocytes and the most abundant (40\% to 75\%) type of white blood cells in most mammals. They form an essential part of the innate immune system and considered as the firstline nonspecific immune defense ingesting the invading microorganisms by process of phagocytosis. Neutrophils kill microorganisms with toxic oxygen radicals and proteolytic enzymes produced during the oxidative burst. Disturbances of any of those essential neutrophils functions may be associated with an increased risk for bacterial infections (9).

Each phagocytic event resulting in the formation of a phagosome with reactive oxygen species (ROS) and secretion of hydrolytic enzymes. The consumption of oxygen during the generation of ROS has been termed the "respiratory burst", although unrelated to respiration or energy production (10).

The relation between increased ROS and decreased phagocytic function of neutrophils may be related to the decrease in a number of these phagocytic cells due to the process of apoptosis, a finding that was demonstrated by several studies $(11,12)$.

\section{Objectives}

IV iron is believed to disturb the phagocytic function of the neutrophils and is known to be a potent pro-oxidant (13). Its harmful impacts of increased neutrophil oxygen burst activity may attribute to repeated bacterial infections in chronic, regular HD patients. We aimed to answer the question whether, there is a difference between the effect of $100 \mathrm{mg}$ IV iron sucrose versus iron dextran on the neutrophil oxidative burst activity by flow-cytometry and C-reactive protein (CRP) titer among ESRD individuals on regular $\mathrm{HD}$.

\section{Patients and Methods \\ Study population}

A crossover research was conducted on 20 end-stage renal disease individuals on chronic regular HD. They were divided randomly into two equal groups of 10 patients, each group received $100 \mathrm{mg}$ single dose of one of common commercially used IV iron preparation iron sucrose or iron hydroxide dextran complex. After a washout period of 4 weeks, each group was shifted to the other type. Full history and clinical examination were conducted. Patients with evidence of acute infection diabetes mellitus, chronic liver disease, active collagen disease or any other acquired immune deficiency diseases were excluded. Patients on immunosuppressive drugs or with hypersensitivity to iron therapy or evidence of iron overload (TSAT $>50 \%$ and/or ferritin $>800 \mathrm{ng} / \mathrm{mL}$ ) were also excluded.

All patients were maintained on erythropoietin maintenance dose with no blood transfusion nor iron therapy for one month before the study. Fresh fasting serum and plasma samples were taken before midweek HD session for assessment of blood urea, blood urea nitrogen (BUN), calcium (Ca), inorganic phosphate, albumin, creatinine (were conducted by Synchron CX-9 autoanalyzer; Beckman instruments division, Fullerton, CA92634, 3100, USA). Additionally, serum ferritin, iron, total iron binding capacity (TIBC), transferrin saturation (TSAT; serum iron/total iron binding capacity) and intact parathyroid hormone (iPTH) by (Cobas e411: Roche diagnostics Gmbh, sandhoferstrasse116, D—68305 Mannheim) were measured. Accordingly, CRP titer was measured by latex immunoassay (plasmatic, Dhanmondi, Dhaka-Bangladesh). Urea reduction ratio (URR) was calculated $(13)$ by URR $=($ Upre - Upost $) /$ U pre $\times 100$. Where Upre is the pre-dialysis urea level and Upost is the post-dialysis urea level.

Around, $2 \mathrm{~mL}$ peripheral blood samples were obtained from all enrolled subjects on ethylenediamine tetra-acetic acid, dipotassium salt (K2-EDTA) in vacutainer tubes (final concentration of $1.5 \mathrm{mg} / \mathrm{mL}$ ) for;

1. $\mathrm{CBC}$ which was conducted by Beckman coulter (HMX hematology analyzer, Coulter Corporation, Miami, FI33116-9015).

2. Flow cytometric assay of an oxidative burst using the dihydrorhodamine123 (DHR 123) (14): Peripheral blood samples were processed on the same day of sample collection. The reagents in this test are (DHR123) and phorbol 12-myristate 13-acetate (PMA) (both supplied from Sigma-Aldrich, St Louis, MO, USA). In making stock solutions, DHR (10 $\mathrm{mg}$ ) was dissolved in $5 \mathrm{~mL}$ of dimethyl sulfoxide (DMSO) ;aliquots of $50 \mu \mathrm{L}$ were then placed into Eppendorf tubes and frozen at $-80^{\circ} \mathrm{C}$. PMA: 1990 $\mu \mathrm{L}$ hanks balanced salt solution (HBSS) were added to $10 \mu \mathrm{L}$ PMA $(1 \mu \mathrm{g} / \mu \mathrm{L})$ the first tube. Then $9 \mathrm{~mL}$ HBSS was added to $1 \mathrm{~mL}$ from the first tube to reach the final dilution $2000 \mathrm{ng} / \mathrm{mL}$ (freshly prepared). These stocks are then aliquoted and stored at $-800^{\circ} \mathrm{C}$ until use. $500 \mu \mathrm{L}$ of patient blood was added to 10 $\mathrm{mL}$ ammonium chloride-based erythrocyte lysing solution (NH4CL) in the patient tube in the dark (Pharm Lyse, Becton Dickinson, Mountain view, CA, 
USA). The tube incubated for 10 minutes at room temperature. Two tubes are set up for each patient stimulated and unstimulated: (a) Blood + DHR123 (unstimulated resting tube); (b) Blood + DHR123 + PMA (stimulated tube). Around $100 \mu \mathrm{L}$ of HBSS was added to unstimulated tubes. Then, $100 \mu \mathrm{L}$ of working dilution PMA was added to stimulated tubes. The tubes were placed into a $37^{\circ} \mathrm{C}$ water bath to preheat. Following 10 minutes lysis the tubes were centrifuged at $1500 \mathrm{rpm}$ for 5 minutes, then the supernatant was removed. The cell pellets were resuspended in $10 \mathrm{~mL}$ of HBSS. The tubes were centrifuged again at 1500 rpm for 5 minutes then the supernatant was removed as above. The cell pellets were resuspended in 2 $\mathrm{mL}$ of HBSS. One milliliter of this suspension was removed. Then $5 \mu \mathrm{L}$ stock DHR was added, mixed and incubated in the $37^{\circ} \mathrm{C}$ water bath for 30 minutes. Stimulated neutrophils undergo the oxidative burst, thereby oxidizing the DHR123 to its resonance form (rhodamine) which is highly green fluorescent when exposed to the $488 \mathrm{~nm}$ laser. The immediate flow cytometric analysis was done (guava easycyte HT, MILLIPORE) using DHR123, $10 \mathrm{mg}$, D632, lot 1226863 and Invitrogen by life technologies).

Mean green fluorescence of stimulated and unstimulated cell was calculated and then stimulation index was performed as follow; stimulation index (ratio) = mean green fluorescence of stimulated/ mean green fluorescence of unstimulated.

Taking into considerations, the half-life of $100 \mathrm{mg}$ iron dextran 30 to 60 hours and cleared from the body after 7 days. Regarding iron sucrose, half- life is 1-8 hours and cleared 24-48 hours in chronic kidney disease patients $(15,16)$. Flow-cytometric evaluation of neutrophilic oxidative burst with calculation of stimulation index and CRP titer were conducted before and after 48 hours of IV iron.

Taking into consideration that, the test is conducted before the upcoming HD session, to eliminate the possible direct effect of HD technique on the neutrophil cells, to study the short-term effect of IV iron dextran versus iron sucrose on one of the phagocytic functions tests of neutrophils.

\section{Ethical considerations}

This study was approved through the local ethics committee of Ain-Shams University hospital. The study has been performed in accordance with the ethical standards laid down in the 1964 Declaration of Helsinki. All the enrolled patients provided informed written consents.

\section{Statistical analysis}

Quantitative data like age, were presented as a minimum, maximum, mean and standard deviation. Qualitative data like gender, were presented as count and percentage. As some of the studied variables were not normally distributed, Wilcoxon signed ranks test was applied to compare paired observations for different groups. Spearman's correlation test was applied to compare the correlation between different continuous variables. Mann-Whitney U test was used to compare quantitative data between two independent groups and KruskalWallis test was used when more than two groups were to be compared. Student t-test was applied to compare quantitative data between two independent groups when the variables are normally distributed. Chi-square test was used to compare qualitative data between different groups. Two way ANOVA test was used to measure the independent effect of two factors on a continuous outcome. Additionally, $P$ value $<0.05$ was considered statistically significant.

Results

Twenty HD patients (9 males and 11 females), with mean age of $49.40 \pm 9.02$ years and mean duration of HD of $10 \pm 7.32$ years were included in this study. The causes of renal failure were hypertension in 5 patients (25\%), chronic glomerulonephritis in 4(20\%), obstructive uropathy in 3 (15\%), chronic pyelonephritis in $3(15 \%)$, analgesic nephropathy in $2(10 \%)$ and unknown etiology in $3(15 \%)$ of total patients. The majority of the studied patients (85\%) were with arteriovenous fistula (AVF) as vascular access. The mean of dry weight was $66.45 \pm 17.47$ $\mathrm{kg}$ and body mass index (BMI) mean was $20.36 \pm 4.84$ $\mathrm{kg} / \mathrm{m}^{2}$. Average erythropoietin dose of 4000 IU/week. Demographic and laboratory data of group I and group II are shown in (Tables 1 and 2). Around 17 (85.0\%) of total patients were non-smokers.

Group I had a basal oxidative burst stimulation index of 6.15 (median), IQR $=1.70$, that significantly increased after administration of iron sucrose dose $(P=0.01)$. Group I had also an increase in CRP titer that was not statistically significant $(P=0.06)$ (Table 3 , Figure 1$)$. There was a highly statistically significant increase in the oxidative burst index in group I after iron dextran dose $(P=0.002)$ and CRP titer $(P=0.03)$ (Table 4, Figure 2).

We had comparable results in group II (Tables 5 and 6;

Table 1. Demographic parameters of the studied groups of hemodialysis patients

\begin{tabular}{lll}
\hline & Group 1 & Group 2 \\
\hline Age (years) & $46.70 \pm 8.91$ & $52.10 \pm 8.74$ \\
Duration of dialysis $(\mathrm{y})$ & $11.20 \pm 8.68$ & $8.80 \pm 5.9$ \\
Dry weight $(\mathrm{kg})$ & $62.40 \pm 13.26$ & $70.50 \pm 20.8$ \\
Height $(\mathrm{cm})$ & $158.90 \pm 7.88$ & $165.90 \pm 8.72$ \\
BMI $\left(\mathrm{kg} / \mathrm{m}^{2}\right)$ & $19.59 \pm 3.6$ & $21.13 \pm 5.94$ \\
SBP $(\mathrm{mm} \mathrm{Hg})$ & $120.00 \pm 21.08$ & $132.00 \pm 22.51$ \\
DBP $(\mathrm{mm} \mathrm{Hg})$ & $77.00 \pm 13.37$ & $80.00 \pm 14.91$ \\
Sex $(\mathrm{M} / \mathrm{F})$ & $3 / 7$ & $6 / 4$ \\
Vascular access (AVF/catheter) & $9 / 1$ & $8 / 2$ \\
\hline
\end{tabular}

BMI: body mass index; SBP: systolic blood pressure: DBP: diastolic blood pressure; M/F: male/female; AVF: arteriovenous fistula 
Table 2. Basal laboratories results of the studied groups of patients

\begin{tabular}{lll}
\hline Basal laboratory data & Group 1 & Group 2 \\
\hline Hemoglobin $(\mathrm{g} / \mathrm{L})$ & $105.4 \pm 11.4$ & $103.0 \pm 12.2$ \\
TLC $\left(10^{9} / \mathrm{L}\right)$ & $6.36 \pm 1.24$ & $5.51 \pm 0.92$ \\
\hline Iron $(\mu \mathrm{mol} / \mathrm{L})$ & $10.60 \pm 2.37$ & $11.69 \pm 1.95$ \\
Ferritin $(\mu \mathrm{g} / \mathrm{L})$ & $262.50 \pm 209.93$ & $188.90 \pm 238.54$ \\
TIBC $(\mu \mathrm{mol} / \mathrm{L})$ & $30.2 \pm 5.89$ & $42.78 \pm 10.26$ \\
Creatinine $(\mu \mathrm{mol} / \mathrm{L})$ & $619.68 \pm 52.41$ & $661.23 \pm 104.31$ \\
URR $(\%)$ & $74.10 \pm 5.1$ & $71.00 \pm 4.97$ \\
Serum calcium (mmol/L) & $1.85 \pm 0.18$ & $1.92 \pm 0.2$ \\
\hline Serum phosphorus (mmol/L) & $1.89 \pm 0.45$ & $1.77 \pm 0.55$ \\
Albumin (g/L) & $42 \pm 5$ & $40.6 \pm 4.8$ \\
iPTH (ng/L) & $765.30 \pm 540.58$ & $576.10 \pm 439.01$ \\
\hline
\end{tabular}

TLC: total leucocytic count; TIBC: total iron binding capacity; URR: urea reduction ratio; iPTH: intact parathyroid hormone.

Table 3. Comparison between neutrophil oxidative burst index and CRP titer before and after introduction of iron sucrose in (group I)

\begin{tabular}{lllll}
\hline & Median & IQR & $Z^{*}$ & P value \\
\hline $\begin{array}{l}\text { Oxidative burst index before } \\
\text { iron sucrose }\end{array}$ & 6.15 & 1.70 & & \\
$\begin{array}{l}\text { Oxidative burst index after } \\
\text { iron sucrose }\end{array}$ & 7.20 & 3.60 & & \\
CRP before(nmol/L) & 4.762 & 19.048 & 2.50 & 0.01 \\
CRP after(nmol/L) & 47.62 & 142.86 & 2.04 & 0.06 \\
\hline
\end{tabular}

*Wilcoxon signed ranks test.

Table 4. Comparison between neutrophil oxidative burst index and CRP titer before and after introduction of iron dextran in group I

\begin{tabular}{|c|c|c|c|c|}
\hline & Median & IQR & $\mathbf{Z}^{*}$ & $P$ value \\
\hline $\begin{array}{l}\text { Oxidative burst index } \\
\text { before iron dextran }\end{array}$ & 7.95 & 7.50 & 2.80 & 0.002 \\
\hline $\begin{array}{l}\text { Oxidative burst index } \\
\text { after iron dextran }\end{array}$ & 18.00 & 14.60 & & \\
\hline CRP before (nmol/L) & 9.524 & 19.048 & 2.21 & 0.03 \\
\hline CRP after (nmol/L) & 119.05 & 190.48 & & \\
\hline
\end{tabular}

*Wilcoxon signed ranks test.

Table 5. Comparison between neutrophil oxidative burst index and CRP titer before and after introduction of iron dextran in group II

\begin{tabular}{lllll}
\hline & Median & IQR & $Z^{*}$ & $P$ value \\
\hline $\begin{array}{l}\text { Oxidative burst index } \\
\text { before iron dextran }\end{array}$ & 9.35 & 7.20 & 2.30 & 0.009 \\
$\begin{array}{l}\text { Oxidative burst index } \\
\text { after iron dextran }\end{array}$ & 10.20 & 7.40 & & \\
CRP before (nmol/L) & 9.524 & 19.048 & 2.21 & 0.016 \\
CRP after (nmol/L) & 119.05 & 238.1 & & \\
\hline
\end{tabular}

*Wilcoxon signed ranks test.

Figures 3 and 4). A highly statistically significant increase in the neutrophilic oxidative burst index $(P<0.001)$ was found 48 hours after administration of both types of IV iron. Two-way ANOVA test showed that $100 \mathrm{mg}$ of IV iron in HD patients caused a highly significant difference in oxidative burst test of neutrophil cells before and after administration of iron regardless of its type $(P<0.01)$. This

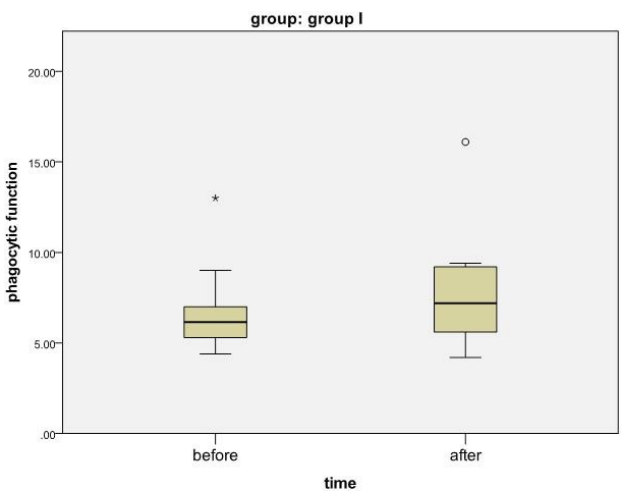

Figure 1. Comparison between neutrophil oxidative burst test before and after the introduction of iron sucrose in group I ( $P$ value: 0.01$)$.

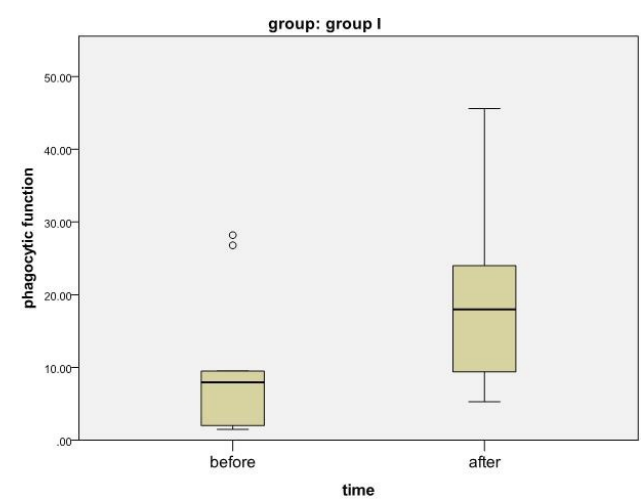

Figure 2. Comparison between phagocytic function by oxidative burst test before and after introduction of iron dextran in group I ( $P$ value 0.002$)$.

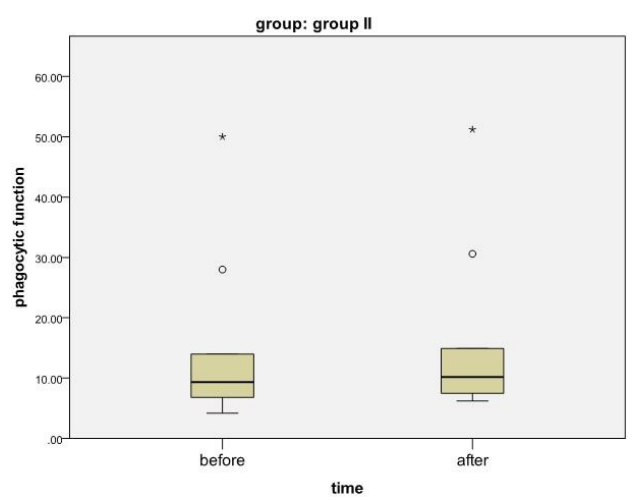

Figure 3. Comparison between phagocytic function by oxidative burst test before and after introduction of type dextran in group II ( $P$ value 0.009).

change over time is not significantly different between two types of iron $(P>0.05)$ (Table 7 , Figure 5$)$.

Neutrophil oxidative burst index and URR \% were found to be negatively correlated $(\mathrm{r}=-0.59, P \leq 0.01)$ as shown in (Figure 6). No statistically significant correlation was observed between neutrophil oxidative index and other studied parameters $(P>0.05$; Table 8$)$. 
Table 6. Comparison between neutrophil oxidative burst index and CRP titer before and after introduction of iron sucrose in group II

\begin{tabular}{lllll}
\hline & Median & IQR & $\mathbf{Z}^{*}$ & $\boldsymbol{P}$ value \\
\hline $\begin{array}{l}\text { Oxidative burst index } \\
\text { before iron dextran }\end{array}$ & 10.15 & 12.10 & 2.80 & 0.002 \\
$\begin{array}{l}\text { Oxidative burst index } \\
\text { after iron dextran }\end{array}$ & 25.65 & 11.80 & & \\
$\begin{array}{l}\text { CRP before (nmol/L) } \\
\text { CRP after (nmol/L) }\end{array}$ & 4.762 & 19.048 & 2.02 & 0.06 \\
\hline
\end{tabular}

*Wilcoxon signed ranks test.

Table 7. Comparison between the two types of iron regarding their effects on neutrophil oxidative burst index in all patients' groups

\begin{tabular}{|c|c|c|c|c|}
\hline \multirow[b]{2}{*}{ Type of iron } & \multirow[b]{2}{*}{ Time } & \multirow[b]{2}{*}{ Mean $\pm S D$} & \multicolumn{2}{|c|}{$95 \% \mathrm{Cl}$} \\
\hline & & & $\begin{array}{l}\text { Lower } \\
\text { Bound }\end{array}$ & $\begin{array}{l}\text { Upper } \\
\text { Bound }\end{array}$ \\
\hline \multirow{2}{*}{ Iron sucrose } & Before & $8.97 \pm 2.1$ & 4.70 & 13.23 \\
\hline & After & $16.94 \pm 2.77$ & 11.32 & 22.56 \\
\hline \multirow{2}{*}{$\begin{array}{l}\text { Iron } \\
\text { dextran }\end{array}$} & Before & $12.28 \pm 2.1$ & 8.01 & 16.54 \\
\hline & After & $18.26 \pm 2.77$ & 12.64 & 23.88 \\
\hline \multicolumn{5}{|c|}{ Two-way ANOVA test } \\
\hline Effect & & $\mathbf{F}$ & \multicolumn{2}{|c|}{$P$ value } \\
\hline Iron & & 0.54 & \multicolumn{2}{|c|}{0.47} \\
\hline Time & & 21.38 & \multicolumn{2}{|c|}{$<0.001$} \\
\hline Time $*$ Iron & & 0.435 & \multicolumn{2}{|c|}{0.51} \\
\hline
\end{tabular}

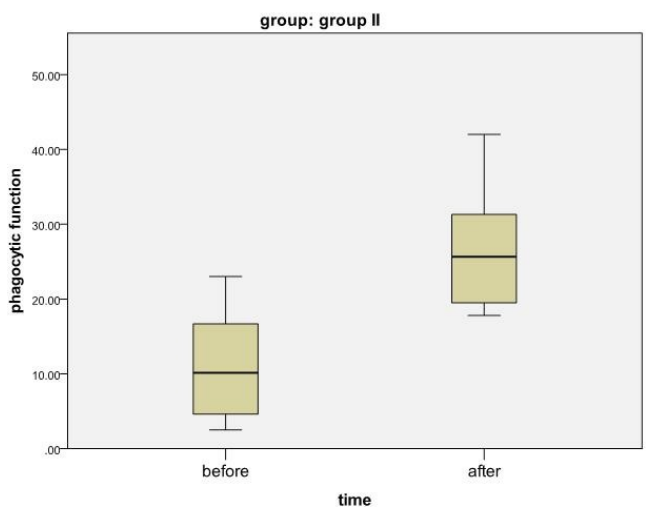

Figure 4. Comparison between phagocytic function by oxidative burst test before and after introduction of iron Sucrose in group II ( $P$ value 0.002).

\section{Discussion}

Bacterial infections are the second most common cause of death in patients with ESRD (17). Although iron is an essential nutrient being necessary for the formation of hemoglobin, iron therapy may affect cytokine production and leukocyte functions, promote oxidative stress enhancing also bacterial growth. It was demonstrated that, high-dose parenteral iron sucrose therapy decreases the killing capacity of polymorphonuclear cell isolated from CKD patients (2). Kidney Disease Improving Global Outcomes (KDIGO) in 2012 and other recent international CKD anemia guidelines advised caution with using IV iron in the setting of infection (18).

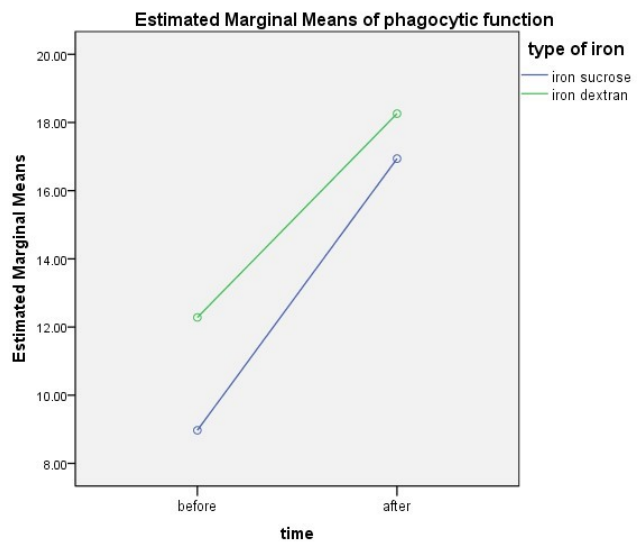

Figure 5. Neutrophil Oxidative burst index as a test of phagocytic function as regard to type and time of introduction of IV iron.

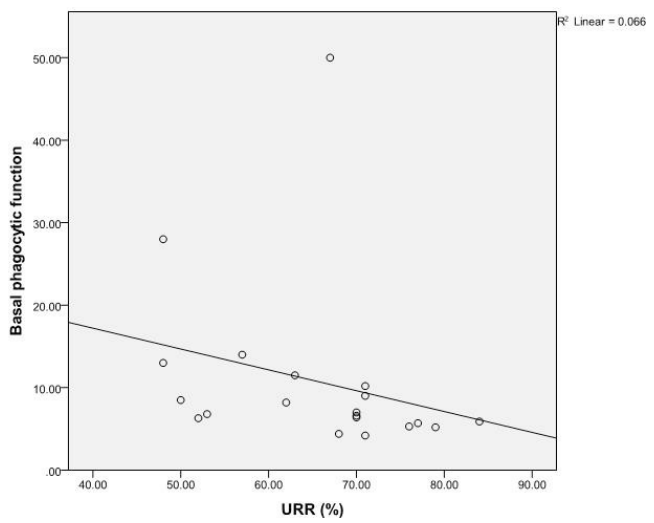

Figure 6. Correlation between URR (\%) and basal neutrophil oxidative burst index.

Table 8. Correlation between lab investigations and basal neutrophil oxidative burst index in all 20 patients

\begin{tabular}{lcc}
\hline & $\mathbf{r}$ & P value \\
\hline Hemoglobin(g/L) & 0.02 & 0.94 \\
TLC $(109 / \mathrm{L})$ & -0.19 & 0.42 \\
Platelets $\left(10^{/} / \mathrm{L}\right)$ & -0.21 & 0.38 \\
Iron $(\mu \mathrm{mol} / \mathrm{L})$ & -0.14 & 0.57 \\
Ferritin $(\mu \mathrm{g} / \mathrm{L})$ & 0.08 & 0.75 \\
TIBC $(\mu \mathrm{mol} / \mathrm{L})$ & 0.13 & 0.58 \\
Creatinine $(\mu \mathrm{mol} / \mathrm{L})$ & -0.05 & 0.83 \\
Urea PRE $(\mathrm{mmol} / \mathrm{L})$ & 0.09 & 0.72 \\
Urea POST (mmol/L) & 0.51 & 0.02 \\
URR $(\%)$ & -0.59 & 0.01 \\
Serum calcium(mmol/L) & 0.07 & 0.76 \\
Serum phosphorus(mmol/L) & -0.14 & 0.55 \\
Serum albumin(g/L) & -0.06 & 0.80 \\
iPTH(ng/L) & -0.21 & 0.38 \\
Basal CRP (nmol/L) & 0.15 & 0.52 \\
\hline
\end{tabular}

However, this recommendation was not graded as limited data from observational studies and conflicting results in HD patients. Some studies reviewed that ESRD may develop a decrease in phagocytic capacity and an increase 
in apoptosis of polymorphonuclear neutrophils (PMNs) $(19,20)$. While HD may transiently intensify these abnormalities from the roller pump, exposure to dialyzer membrane, and influx of impurities from the dialysate compartment (20). PMNs recognize pathogens via tolllike receptors triggering phagocytosis (21). Oxidative burst is one of the most important functions that enable the neutrophils to effectively eliminate the pathogen during phagocytosis. Changes of neutrophil respiratory burst may reflect an increased susceptibility to infection (22).

In the present cross over study, we included 20 ESRD patients on regular HD randomly selected. We studied the effect of two commonly used IV iron products (iron sucrose, iron dextran) on both inflammatory marker titer (CRP) and neutrophil oxidative burst as one of phagocytic function tests of neutrophils assessed by flow cytometry. There was a statistically significant increase of oxidative burst stimulation index after administration of $100 \mathrm{mg}$ IV iron regardless of its type (iron sucrose or iron dextran) after 48 hours from the dose with no significant difference between two types of iron. The increase in CRP titer after administration of both types of IV iron was observed with a statistically significant increase after iron dextran. In the absence of iron overload or infection, single dose of 100 mg of IV iron (iron sucrose or iron dextran) in chronic HD patients may change the neutrophil oxidative respiratory burst and may alter the phagocytic function of neutrophils which may lead to increase susceptibility to infection in HD patients. The relationship between increased ROS and decrease phagocytic function of neutrophils may be related to the decrease of number of these phagocytic cells due to process of apoptosis (23), which occur as follow; when ROS generation increases intracellularly, this leads to increased intracellular oxidative stress that may predispose PMN cells to membrane destabilization (lysosomal and mitochondrial), oxidative modification of cellular macromolecules, inhibit protein function and finally promoting cell death.

Only a couple of studies have examined differences among formulations of iron. Some studies reviewed the association with incidence of sepsis and bacteremia mainly with iron sucrose in $\operatorname{HD}$ patients $(1,2)$. The study by Ichii et al, on the in vitro effect of iron sucrose with different concentrations, showed that incubation of PMNs caused significant concentration dependent suppression of phagocytic function against both Staphylococcus aureus and Escherichia coli and also a significantly concentration dependent increase in apoptotic PMNs (17). In contrast, Deicher et al conducted a study which included 20 ESRD on regular peritoneal dialysis. Around, 10 patients received $300 \mathrm{mg}$ IV iron sucrose while, the other 10 patients were placebo received normal saline. They found that the iron treatment group had a lower overall percentage of killed E. coli. However, the basal and stimulated oxidative burst by flow cytometry were comparable between groups and stable over time within subjects (24).

Patruta et al assessed neutrophil impairment associated with iron therapy. They found more significant neutrophil impairment in $\mathrm{HD}$ patients with functional iron deficiency (ferritin $>650 \mu \mathrm{g} / \mathrm{L}$ and transferrin saturation $<20 \%$ ). They also found a significant inhibition of PMNs intracellular killing of bacteria and PMNs oxidative burst which was significantly increased after administration of IV iron-saccharate in their patient (25). Similarly, Pai et al, observed that both iv iron dextran and sucrose produced similar ROS generation and cytokine activation that was more pronounced among ESRD patients (26).

In the present study both commercial types of IV iron (dextran or sucrose) significantly increased the neutrophil cells oxidative burst stimulation index after 48 hours, that may lead to apoptosis of cells and impair the phagocytic function of the neutrophil cells as the main cells of innate immunity in HD patients.

\section{Conclusion}

In this study we found the administration of $100 \mathrm{mg}$ dose of either IV iron dextran or iron sucrose had a hazardous effect on the neutrophilic phagocytic function in HD patients. The oxidative burst index estimated by flow cytometry significantly increased in the absence of infection or iron overload, with no significant difference between both types of iron. However, further studies are warranted to determine the proper dose of IV iron and the best type of iron therapy with the least harmful effect on neutrophil phagocytic functions among ESRD patients.

\section{Limitations of the study}

The small sample size (20 patients) in our study is considered a limitation and that was because the study did not receive any funds to help increasing its size.

\section{Conflicts of interest}

The authors declare that they have no potential conflicts of interest to disclose.

\section{Ethical considerations}

Ethical issues (including plagiarism, data fabrication, double publication) have been completely observed by the authors.

\section{Funding/Support}

This research did not receive any specific grant from funding agencies in the public, commercial, or not-forprofit sectors.

\section{References}

1. Sirken G, Raja R, Rizkala AR. Association of different intravenous iron preparations with the risk of bacteremia in maintenance hemodialysis patients. Clin Nephrol. 2006; 
66:348-56

2. Diskin CJ, Stokes TJ, Dansby LM, Radcliff L, Carter TB. Is systemic heparin a risk factor for catheter-related sepsis in dialysis patients? An evaluation of various biofilm and traditional risk factors. Nephron Clin Pract. 2007;107:c128132. doi: 10.1159/000110032.

3. Teehan GS, Ruthazer R, Balakrishnan VS, Snydman D, Jaber $\mathrm{BL}$. Iron storage indices and risk of bacterial infections in 10.1111/j.1492-7535.2004.01100.x.

4. Macdougall IC, Chandler G, Elston O, Harchowal J. Beneficial effects of adopting an aggressive intravenous iron policy in a hemodialysis unit. Am J Kidney Dis. 1999; 34:S40-6. doi: 10.1053/ajkd.1999.v34.aajkd0344b0.

5. Jenq CC, Hsu CW, Huang WH, Chen KH, Lin JL, Lin-Tan DT. Serum ferritin levels predict all-cause and infectioncause 1-year mortality in diabetic patients on maintenance hemodialysis. Am J Med Sci. 2009;337:188-94. doi: 10.1097/ maj.0b013e31818d8bbe.

6. Galic G, Tomic M, Galesic K, Kvesić A, Soljić M, Londar Z, et al. The etiological relation between serum iron level and infection incidence in hemodialysis uremic patients. Coll Antropol. 2011;35:93-101.

7. Teehan GS, Bahdouch D, Ruthazer R, Balakrishnan VS, Snydman DR, Jaber BL. Iron storage indices: novel predictors of bacteremia in hemodialysis patients initiating intravenous iron therapy. Clin Infect Dis. 2004;38:1090-4. doi: $10.1086 / 382878$.

8. Teehan GS, Ruthazer R, Balakrishnan VS, Snydman D, Jaber $\mathrm{BL}$. Iron storage indices and risk of bacterial infections in hemodialysis patients. Hemodial Int. 2004; 8:226-32. doi: 10.1111/j.1492-7535.2004.01100.x.

9. Chonchol M. Neutrophil dysfunction and infection risk in end-stage renal disease. Semin. Dial. 2006;19:291-6. doi: 10.1111/j.1525-139X.2006.00175.x.

10. Segal AW. How neutrophils kill microbes. Annu Rev Immunol. 2005;9:197-223. doi: 10.1146/annurev. immunol.23.021704.115653.

11. Circu ML, Aw TY. Reactive oxygen species, cellular redox system, and apoptosis. Free Radic Biol Med. 2010; 486:74962. doi: 10.1016/j.freeradbiomed.2009.12.022.

12. Matés JM , Sánchez-Jiménez FM . Role of reactive oxygen species in apoptosis: implications for cancer therapy. Int J Biochem Cell Biol. 2000;32:157-70.

13. Owen WF, Lew NL, Liu Y, Lowrie EG, Lazarus JM .The urea reduction ratio and serum albumin concentration as predictors of mortality in patients undergoing hemodialysis. N Engl J Med. 1993;329:1001-6. doi: 10.1056/ NEJM199309303291404.

14. Richardson MP, Ayliffe MJ, Helbert M, Davies EG. A simple flow cytometry assay using dihydrorhodamine for the measurement of the neutrophil respiratory hemodialysis patients. Hemodial Int. 2004; 8:226-232. doi:

burst in whole blood: comparison with the quantitative nitrobluetetrazolium test. J Immunol Methods 1998;219:187-93.

15. Danielson BG. Structure, chemistry, and pharmacokinetics of intravenous iron agents. J Am Soc Nephrol. 2004;15:S9398. doi: 10.1097/01.ASN.0000143814.49713.C5.

16. Hayat A. Safety Issues with Intravenous Iron Products in the Management of Anemia in Chronic Kidney Disease. Clin Med Res. 2008;6:93-102.doi: 10.3121/cmr.2008.811.

17. Ichii H, Masuda Y, Hassanzadeh T, Saffarian M, Gollapudi S, Vaziri N. Iron Sucrose Impairs Phagocytic Function and Promotes Apoptosis in Polymorphonuclear Leukocytes. Am J Nephrol. 2012;36:50-7. doi: 10.1159/000339285.

18. Deicher R, Horl WH. Anaemia as a risk factor for the progression of chronic kidney disease. Curr Opin Nephrol Hypertens 2003;12:139-43. doi: 10.1097/00041552200303000-00003.

19. Kidney Disease Improving Global Outcomes (KDIGO) Anemia Work Group. KDIGO Clinical Practice Guideline for Anemia in Chronic Kidney Disease. Kidney Int Suppl. 2012;2:279-335. doi: 10.1038/kisup.2012.37.

20. Yoon JW, Pahl MV, Vaziri ND. Spontaneous leukocyte activation and oxygen-free radical generation in end-stage renal disease. Kidney Int. 2007;71:167-72. doi: 10.1038/ sj.ki.5002019.

21. Gollapudi P, Yoon JW, Gollapudi S, Pahl MV, Vaziri ND. Leukocyte toll-like receptor expression in end-stage kidney disease. Am J Nephrol. 2010;31:247-54. doi: $10.1159 / 000276764$.

22. Gessler P, Nebe T, Birle A, Haas N, Kachel W. Neutrophil respiratory burst in term and preterm neonates without signs of infection and in those with increased levels of C-reactive protein. Pediatr Res. 1996;39:843-848. doi: 10.1203/00006450-199605000-00017.

23. Circu ML, Aw TY. Reactive oxygen species, cellular redox system, and apoptosis. Free radical biology \& medicine 2010; 48:749-62. doi: 10.1016/j.freeradbiomed.2009.12.02.

24. Deicher R, Ziai F, Cohen G, Müllner M, Hörl WH. High-dose parenteral iron sucrose depresses neutrophil intracellular killing capacity. Kidney Int. 2003;64:728-36. doi: $\quad 10.1046 / j .1523-1755.2003 .00125 . x$.

25. Patruta SI, Edlinger R, Sunder-Plassmann G, Hörl WH. Neutrophil impairment associated with iron therapy in hemodialysis patients with functional iron deficiency. J Am Soc Nephrol. 1998;9:655-63.

26. Pai AB1, Conner T, McQuade CR, Olp J, Hicks P. Nontransferrin bound iron, cytokine activation and intracellular reactive oxygen species generation in hemodialysis patients receiving intravenous iron dextran or iron sucrose. Biometals. 2011;24:603. doi: 10.1007/s10534-011-94096.

Copyright $\odot 2020$ The Author(s); Published by Published by Society of Diabetic Nephropathy Prevention. This is an open-access article distributed under the terms of the Creative Commons Attribution License (http://creativecommons.org/licenses/by/4.0), which permits unrestricted use, distribution, and reproduction in any medium, provided the original work is properly cited. 